Article

\title{
Inclusions and Exclusions in Rural Tanzanian Primary Schools: Material Barriers, Teacher Agency and Disability Equality
}

\author{
Susie Miles ${ }^{1, *}$, Jo Westbrook ${ }^{2}$ and Alison Croft $^{3}$ \\ ${ }^{1}$ Manchester Institute of Education, University of Manchester, Manchester, M13 9PL, UK; \\ E-Mail: susie.miles@manchester.ac.uk \\ ${ }^{2}$ Centre for International Education, University of Sussex, Brighton, BN1 9RH, UK; E-Mail: jlw24@sussex.ac.uk \\ 3 Independent Consultant, UK; E-Mail: alison.croft.14@ucl.ac.uk \\ * Corresponding author
}

Submitted: 1 October 2017 | Accepted: 14 February 2018 | Published: 26 March 2018

\begin{abstract}
This article begins with the assumption that the argument for the inclusion of children with disabilities in mainstream schools, championed by Sustainable Development Goal 4 and Article 24 of the UN Convention on the Rights of Persons with Disabilities, has largely been accepted nationally and internationally by policy makers, and is increasingly being accepted by teachers. In interrogating the complex craft of developing inclusive and equal learning environments for children with disabilities, this article draws upon Kershner's 'core aspects of teachers' knowledge and knowing', and in particular, 'the school as a site for the development of teaching expertise and the creation of knowledge'. Data is presented from indepth interviews following videoed lesson observations with experienced teachers in 15 rural, urban and coastal primary schools in four districts in Tanzania. Findings indicate that the teachers' practice is moving unevenly towards disability equality, and involves processes of inclusions and exclusions. This involves teacher autonomy, agency and reflective practice in the context of material, attitudinal, structural, pedagogic and curricular barriers. The teachers' expertise has potential to inform national and international policy developments, and so reduce the evident rhetoric-reality gap. In conclusion, it is argued that inclusive education needs to grapple with disability as a social construct, and lessons are drawn for the further fulfilment of the rights of children with disabilities to equal participation in education.
\end{abstract}

\section{Keywords}

disability; inclusive education; pedagogy; primary school; rights; Sustainable Development Goals; Tanzania

\section{Issue}

This article is part of the issue "Disability Equality: In Theory and Practice", edited by Mark Priestley (University of Leeds, UK) and Lisa Waddington (Maastricht University, The Netherlands).

(C) 2018 by the authors; licensee Cogitatio (Lisbon, Portugal). This article is licensed under a Creative Commons Attribution 4.0 International License (CC BY).

\section{Introduction}

This article critically explores the current international policy context in relation to disability equality in education and its implementation by ordinary primary school teachers in mainstream schools in Tanzania. The research question framing the article is: how can rural primary school teachers' experience inform the development of more disability equal educational policy and practices? This article is timely because it highlights the disconnect between the grand global debates which support disability equality in education, and the limited availability of relevant pre- and in-service teacher education. This article also contributes to the limited and scattered literature on effective and equitable classroom practice in the global South from a disability equality and inclusive education perspective.

We begin by identifying the guiding global debates on education for all, inclusive education and disability equality that demonstrate increasing evidence of 'equal recog- 
nition' at an international and national policy level. We then consider some of the key legal obligations outlined in the General Comment 4 (Committee on the Rights of Persons with Disabilities, 2016), which builds on Article 24 to provide a framework for a human rights approach to inclusive education. In order to avoid confusion with the Convention on the Rights of Persons with Disabilities (UN, 2006), henceforth we refer to the Committee's General Comment on Article 24 simply as the 'General Comment'.

The scarcity of research and training on inclusive pedagogy in the global South means that teachers who are at the frontline of realising disability rights in education receive little guidance on best practice. Seeking to address this gap in the literature, we present interview data from 15 Tanzanian primary schools that reflect teachers' constructions of disability in their day-to-day teaching of early reading and mathematics. The socialist history of Tanzania, the long-term commitment to inclusion of disabled children and the Africanist policies of its first President, Julius Nyerere, are likely to have had a powerful influence on some of these teachers' generally positive practices.

Inclusive education, we argue, needs to grapple with disability as a social construct given the structural inequalities in post-colonial contexts, and global imbalances of power. Singal and Muthukrishna (2014) have rightly expressed their concern that the models which frame international discussions are 'exclusively anchored in the industrialised, liberalised, individualistic scripting of the North' (p. 294). Indeed, Grech (2014, p. 130) argues that:

Disability discourse including that on inclusive education continues to be fabricated in the global North and transferred to the global South, with little or no alertness to context or culture, or how this discourse is framed, applied (or otherwise) or even resisted in practice.

While we concur with these sentiments, in our understanding inclusive education 'also goes beyond the inclusion of disabled learners...to an examination of the threats to equity which may exist in a particular context' for all learners (Miles, 2009a, p. 22).

As educationalists, we consider the concept of inclusive education to be about removing physical, attitudinal and structural barriers and enabling the social and academic participation of all learners, while recognizing the specific barriers some children with disabilities can face in mainstream settings. However, we also recognise that education cannot be seen in isolation from the competing priorities of poor, rural families who often have to 'choose between education and more basic needs, in particular feeding and medicating the disabled person' (Grech, 2014, p. 141). Barriers to equal participation are not only within the primary classroom, but relate to nutrition, transport to and from school, family and community attitudes and relevance and accessibility of the language of education and of the curriculum. International discussions have tended to overlook local understandings of inclusion and the fact that education for 'all' does not always mean 'all', so efforts to do need to be made to prevent the exclusion of children with disabilities from education (Miles \& Singal, 2010).

The theoretical stance of this article has been influenced by the notion of 'inclusions' and 'exclusions' coexisting in practice and being part of an ongoing process of development (Dyson, 1999). We are aware that the 'different theoretical notions of inclusion are constructed [and] arise from different discourses' (Dyson, 1999, p. 36), and that the Tanzanian teachers' discourse is almost certainly influenced, though not dominated by, medical constructs of disability. Our analysis has been further informed by Kershner's (2014, p. 854) core aspects of teachers' knowledge and knowing about disability, as we recognise that "schools can be sites for the development of teaching expertise and the creation of knowledge" alongside the development of 'specialist' expertise on disability equality and inclusive pedagogy emerging from teachers' practice.

\section{Increasing Recognition of Disability Equality in Education}

The Education 2030 Framework for Action has been created to guide global efforts to reach the most vulnerable and marginalised children. It stresses that 'every learner matters and matters equally' (UNESCO, 2017, p. 13). Sustainable Development Goal 4 commits governments to 'addressing all forms of exclusion and marginalization, disparities and inequalities in access, participation and learning outcomes' at all levels of education from early childhood through to tertiary and lifelong learning. In pushing for transformation rather than steady linear progression, it also claims that:

Inclusion and equity in and through education is the cornerstone of a transformative education agenda, and we therefore commit to addressing all forms of exclusion and marginalization, disparities and inequalities in access, participation and learning outcomes.

Children with disabilities have the dual protection of the Convention on the Rights of the Child (UN, 1989) - which guarantees protection from 'discrimination of any kind, irrespective of the child's or his or her parent's or legal guardian's race, colour, sex, language, religion, political or other opinion, national, ethnic or social origin, property, disability, birth or other status' (Article 2)-and the Convention on the Rights of Persons with Disabilities (Article 24) which specifies the right to access 'inclusive, quality and free primary and secondary education on an equal basis with others in the communities in which they live'.

Educationalists do not always recognise the critical role played by the disability rights movement in advocat- 
ing and lobbying for mainstreaming and inclusion in education over many decades, and in the Convention on the Rights of Persons with Disabilities (CRPD) process (Malinga \& Gumbo, 2016). The United Nations (UN) Standard Rules on the Equalization of Opportunities for Persons with Disabilities (UN, 1993) deployed the disability equality concept explicitly, for example:

Inclusion and participation are essential to human dignity and to the enjoyment and exercise of human rights. Within the field of education, this is reflected in the development of strategies that seek to bring about a genuine equalization of opportunity. (para. 6)

The Salamanca Statement (UNESCO, 1994) built on the Standard Rules and referred to equality of access, equality of opportunity and gender equality. There was much less emphasis on disability equality in the Dakar Framework for Action (UNESCO, 2000), which instead referred to the need for 'special treatment' for children with disabilities. Critically, however, Article 24 is wide open to interpretation, enabling schools to determine whether 'reasonable adjustments' can or cannot be made for some children with disabilities, and therefore equal access and treatment are often denied. The General Comment now provides governments, international agencies, ministries of education, teacher education colleges and schools with detailed, practical guidelines on making inclusive education a reality. For example, Paragraph 35 of the General Comment specifies that all teachers should be trained in the human rights model of disability which we discuss later.

So, while political will and international rhetoric have never been so strong in supporting governments to provide equal access to education for the most vulnerable children:

Frameworks of accountability and performativity are defended by governments on the basis of inclusion, entitlement and equity when evidence points to the injustices produced by such frameworks for both professionals and those for whom they are responsible. (Allan, 2010, p. 607)

Indeed, SDG4 targets, particularly on literacy and numeracy, mean that stakes are high, and countries in the global South experience unreasonably high levels of surveillance in their continued subaltern positioning as they strive towards the development of western style services and aspirational ideals:

European nations developed formal disability services slowly from the early nineteenth century onwards, within the means of their economies, without the censorious gaze of wealthy foreign monitors, and with decades of ongoing debate about methods and strategies. Whatever 'mistakes' they now, with the hindsight of history, may appear to have made seldom looked or felt like mistakes but seemed the best compromise at the time between idealism, realism, resources and knowledge. By contrast, economically weaker countries...have a plethora of modern knowledge, techniques and conflicting advice offered them, but lack the space, time and freedom to experiment for themselves. (Miles \& Hossain, 1999, p. 82)

Rather than being seen as another global policy of surveillance, the CRPD is 'projected as a development tool critical in eliminating poverty' (Winzer \& Mazurek, 2017 , p. 3). Education continues to be recognised as a key factor in lifting people out of poverty, and not just as a mechanism for realising human capital, but central to social justice and basic freedom (Terzi, 2008). The recognition that all children have a right to education as a matter of justice challenges those education systems which still consider some children with disabilities to be ineducable and so continue to be denied their rights to equal access. The additional danger of the preoccupation with access, or 'getting children into school', however, is that dialogue about the many and various 'inclusions' does not take place, and inclusion is reduced to a basic concern with 'place' (Dyson, 1999, p. 49).

The notion of what it means to be included in a particular cultural context tends to be neglected in the inclusive education literature. Concerns have rightly been expressed that inclusive education, as conceived in Northern contexts, places a disproportionate emphasis on the rights of individuals and that this can, in turn, pose risks to long-established social systems, and collectivist ways of being on which family and community stability and solidarity rely in contexts of chronic poverty (Grech, 2014). Having had personal experience of growing up with a disability in a rural area of Tanzania, Kisanji (1998) has written a great deal about the inherent inclusivity of traditional African communities. He has questioned the appropriateness of importing concepts of inclusion developed in Northern contexts and argues that Tanzania's 'customary education principles of universality, relevance, functionality and community localization are central to the success of an inclusive education system' (Kisanji, 1998, p. 54).

At the level of national government, the General Comment reinforces this 'responsibility for the education of persons with disabilities at all levels, together with the education of others, must rest with the education ministry' (para. 58). At the same time, it emphasises the importance of inter-sectoral collaboration and commitment to inclusive education, acknowledging that inclusive education, 'cannot be realized by education ministries in isolation' (para. 59), and clarity about ministerial responsibility and financing for disability in education is essential for disability equality (WHO, 2011). A prime example of the need for ministerial collaboration relates to material concerns for water, sanitation, textbooks, hearing and vision tests, eyeglasses, crutches, wheelchairs, hearing aids, and magnifiers, all of which un- 
derpin inclusive education, yet are the primary responsibility of Health or Social Care. 'Medical' concerns, such as the lack of availability and affordability of eyeglasses (Glewwe, Park, \& Zhao, 2016), are often neglected in research and development programmes, yet they are one of the reasons why so many children drop out of school. The importance of assistive technology to inclusion is addressed by Articles 26 and 32 of the CRPD, and the General Comment acknowledges that the absence of assistive technologies represents a fundamental material barrier to inclusive education-an issue recognized by the World Health Organisation (WHO, 2014).

The General Comment suggests that teachers should take courses focused on the human rights model of disability, inclusive pedagogy, and on 'how to identify students' functional abilities-strengths, abilities and learning styles-to ensure their participation in inclusive educational environments' (para. 69). This would help to balance the current emphasis on 'special education', and would need to be managed carefully to ensure that teachers understand the intersectionality between disability and gender, poverty, ethnicity and sexuality, for example, so that their practice becomes more inclusive of all learners. Currently, however, these finer points of classroom practice are left to ordinary classroom teachers, despite global advocacy for disability equality and UN commitment to inclusion.

Literature on inclusive classroom practice and learning processes in Southern countries remains scarce. There is a disproportionate focus on teacher attitudes as well as on 'access and attendance, with less attention paid to what happens within classrooms' (Wapling, 2016, p. 2). This supports the findings of a rigorous literature review of effective pedagogies in developing countries which found only two papers on inclusive pedagogies of sufficient quality to be included (Westbrook, Durrani, Brown, Orr, \& Pryor, 2014). We argue in this article that enquiries into processes and causes of 'inclusions and exclusions' will have a greater impact on disability equality in education than the measurement of academic outcomes and increased surveillance.

\section{Introducing the Tanzanian Context}

Tanzania has 29 special schools and 239 units attached to mainstream schools serving its population of 54 million, and it is estimated that approximately $3 \%$ of the school age population has a disability. Disability is cited by $2.8 \%$ of children aged 7-16 years as the reason for dropping out of school, and 'more than half of children with disabilities aged 7-16 years who were not attending school said that this was due to disability or illness' (Riggall \& Croft, 2016, p. 82).

Tanzania led the way in East Africa in explicitly including children with disabilities through its Education Act in 1969. The Constitution prohibited discrimination against people with disabilities in 1977, and the Law of the Child, enacted in 2009 , has effectively adopted the Convention on the Rights of the Child and the CRPD was ratified in 2009. The Persons with Disabilities Act of 2010 is supportive of a rights-based view of disability with an overt focus on equal participation. This Act includes a duty to report parents and caregivers in the case of any infringements of the right to education of their children with disabilities. It also states that: 'every child with disability shall attend an ordinary public or private school except where a need for special communication is required' (The United Republic of Tanzania, 2010, p. 24), and Tanzania is one of the few African countries to have legislated for the right to assistive devices (Riggall \& Croft, 2016).

The data we are presenting in this article formed part of a much larger study, The Teacher Preparation in Africa, 2010-11, funded by the William and Flora Hewlett Foundation, which compared primary school trainees' knowledge and ability to teach early reading and mathematics with Newly Qualified Teachers (NQTs) and experienced teachers in Ghana, Kenya, Mali, Senegal, Tanzania and Uganda (Akyeampong, Pryor, Lussier, \& Westbook, 2013; Pryor, Akyeampong, Westbrook, \& Lussier, 2012). The second author was the Principal Investigator of the research in Tanzania and Uganda. Teachers gave informed written consent knowing that they could withdraw at any time, and full ethical approval was granted by the institutions involved in each context. As is the case with most educational research, there was no overt focus on inclusion or disability equality.

One of the unexpected early findings during the field work was the richness of the data emerging in Tanzania. The experienced (mostly female) teachers in Tanzania were remarkably aware and imaginative in their teaching of children with disabilities, yet disability was not mentioned by any of the teachers in the other five countries. Opportunistically, the research team made a decision to focus specifically on teachers' views and practices of disability equality in the classroom in the subsequent interviews. The full data set comprised questionnaires from trainees, NQTs and experienced teachers from four locations (one rural, two metropolitan and one coastal), as well as interviews and focus group discussions with teacher educators and trainees at four representative teacher training colleges, videoed observations of teaching and interviews with 39 NQTs from 24 schools and with 15 experienced teachers who had participated in Continuing Professional Development (CPD) programmes for reading and mathematics. The focus of this article is on the latter group of 15 teachers.

All interviews took place in Kiswahili and were translated by a Kenyan teacher of the deaf with doctoral experience. Transcripts were analysed thematically by the authors from the perspective of how and why all learners were included, and teachers' constructions of inclusions and exclusions in day-to-day classroom practices. Teachers talked confidently about, and readily identified, children with disabilities who were attending school 'as normal' (Dyson, 1999, p. 39). They spoke about children who were blind, visually impaired, had albinism, hearing im- 
pairments, or who were 'short' and stunted through malnutrition, had physical impairments, and cognitive impairments, who they referred to as 'slow learners'. Some children had to sit on the floor because there were not enough chairs and desks, nor were there sufficient textbooks. The first few years of formal learning are particularly critical for children from economically poor backgrounds, given that approximately 250 million children, many of whom have disabilities, fail to attain minimum standards of literacy and numeracy even after attending four years of primary school (UNESCO, 2012).

We have selected data which is representative of the 15 experienced teachers ( 13 women, 2 men) from 15 different primary schools, who have had between five and 37 years of experience, and teach classes of $60-80$ children in the first three years of primary school. Pseudonyms have been used to protect their identities, and are presented here with the number of years they have been teaching: Sophia (5 years); Justina (14 years); Joyce (15 years); Rose (22 years); and Catharine (37 years). We consider the processes through which these teachers have developed inclusive pedagogies and highlight how their practices can inform policies on disability equality in education. In addition to Dyson's (1999) concept of inclusions and exclusions, we have drawn upon Kershner's (2014) core aspects of teachers' knowledge and knowing through dialogue within and beyond the teaching profession. Although this framework is based on research in England, it provides a useful structure for monitoring the development of 'specialist' expertise as it emerges from practice:

1. The importance of understanding child development and learning in context;

2. Reflection and imagination: the value of knowing that you do not know everything and believing that change is possible;

3. The need to communicate understanding and resolve differences between the people who have useful knowledge: a relational process;

4. The need to recognise the school as a site for the development of teaching expertise and the creation of knowledge (Kershner, 2014, pp. 852-854).

The General Comment also encourages all stakeholders to collaborate and problem-solve in line with Kershner's (2014) core aspects, therefore acknowledging the relational process involved in developing 'specialist' expertise. Of the 88 experienced Tanzanian teachers surveyed in this study, only one had attended a course about inclusion, and only $53(63.3 \%)$ reported having received training on reading, mathematics and 'participatory' childcentred methods, mostly through upgrading qualifications rather than bespoke CPD. These teachers have, therefore, developed their knowledge and expertise unevenly, over time and without being connected to national or international debates about disability equality and inclusion.

\section{Rural Primary Schools as Sites for the Development of Disability-Focused Expertise}

The experienced teachers' knowledge and expertise needs to be seen in relation to the younger, less experienced NQTs, who demonstrated positive attitudes towards children with disabilities, but did not teach equitably. Indeed, the NQTs reported their difficulties in identifying and adequately responding to the large group of 'slow learners' in their classes, and that they used generic, rather than individualised, strategies, such as repetition. However, their socio-cultural view of learners led them to blame the shortage of resources and the narrow curriculum for the difficulties they faced, rather than locating the 'problem' within the learners (Westbrook \& Croft, 2015).

What is striking about the more experienced teachers is that they demonstrated considerable skills in their attempts to include all children, and acute awareness of how they exclude children with disabilities in various ways. Sophia reports a big shift in her attitudes following a short training course on inclusion:

At first I considered these kids [with disabilities] as a disturbance to my class because you may be teaching then a kid come and ask you to take him/her to the toilet. Then you have to stop teaching and attend him/her. But after attending that seminar we were told to love them, so now I feel normal.....The environment of the child may affect his/her learning. So, the training helped me a lot!

This instruction to 'love' the children with disabilities constituted the removal of an exclusionary barrier in Sophia's attitude towards the child who needed personal assistance. By enacting this newly acquired knowledge and 'learning in context' (Kershner, 2014, p. 852), Sophia developed a sociocultural construction of disability. Similarly, Arbeiter and Hartley (2002) found that daily exposure to children with disabilities enabled teachers in Uganda to create the conditions conducive to teaching inclusively.

However, the large class sizes meant that teachers were unable to attend to, or physically reach, all the children. Catharine points out that when movement is restricted in overcrowded classrooms selecting 3-4 pupils who answer correctly is an indication that the lesson went on well'. Faced with these physical barriers, checking on learning at all in this context could be viewed as an achievement (Westbrook \& Croft, 2015). It was noticeable that some teachers tended to focus on children with their hands up, those who were mobile and so able to walk to the chalkboard, or who were simply seated at the front. Yet teachers reported moving learners with visual and physical disabilities, and those who were 'short', to the front of the classroom so that they could see and hear the teacher. This enabled children who needed the most help to be situated in the heart of the classroom. Al- 
though apparently a simple intervention, the act of 'insisting' that the children were seated at the front so that they could see well demonstrates teachers' agency. In an earlier study in a Tanzanian primary school, Mmbaga (2002) observed children with visual impairments being seated on the front row by teachers, and then being mostly overlooked-similarly, the least academically able were seated at the back and were rarely paid any attention.

The movement of the subject specialist teachers every 30 minutes to another class, or the change of focus to another subject in the same class, meant that pedagogical practice and appropriate seating were not always consistent, or possible. Justina accepted that many children were marginalised from, and not engaged in learning. Teachers resorted to writing words and calculations on the chalkboard, which was not visible from the back of the class. Textbook shortages meant that all children experience daily inequities, and teachers have become accustomed to teaching inequitably. Justina acknowledged that she often selected 'the few trusted ones' who can read well to hold the textbook 'to represent the others', and sometimes resorted to punishment:

Sometimes, to be frank, I give them some punishments so that I am able to control the class so that they do not make noise but instead listen to what is being read.

In contrast to the NQTs' classrooms, the experienced teachers had homemade charts and teaching materials on display, and several teachers had adapted these specifically for children with disabilities, as Rose reports:

My manila [paper] had large font size and it was also a little bit bold. Also, all other items had white colour. The aim was to enable albino students to see well because they have partial visual impairment. That is why I was asking them...'can you see well'?

Writing in large font on the chalkboard, and using manila sheets to enable students with albinism to learn, are specific pedagogical adaptations, and indicate that inclusion for Rose is not only physical, social or medical, but determined by the level to which children with disabilities are enabled to grasp academic content. Rose explained that she refers to circular objects, such as dinner plates, to link the concept of a circle in mathematics lessons to children's existing knowledge. She also instructed children with visual impairments to feel the shape of their desk as an example of a rectangle. Here is imagination and reflection in action (Kershner, 2014). Rose and Justina used Braille texts routinely in their teaching practice. In response to the question, 'If you had a class without students with special educational needs, would you have used different methods?' Rose replied:

No! I would have used the same methods because it's not that the methods I use are for helping only the students with special needs, but also the rest. Maybe if there were the blind then we would have to have their reading tools. Even the ones who can see can use them. So the teaching aid and the methods that I used here I could also use then.

Rose's epistemological construction of disability and her teaching practice benefit all learners, rather than privileging only a few. Another of the 'varieties' of inclusions identified involved Sophia's use of singing and patient repetition:

I go slowly, step by step, teaching them basic things, not like the way I do for others. For example, for these children I can just say give me two things, then I write him number two and ask him to spell it by singing. But tomorrow he may forget and you start again.

Sophia added, 'So they don't go far'. While this could indicate a deterministic, medical construction, Sophia assumes capability by differentiating learning through spelling and persisting with this, even while recognizing that progress can be slow. Sophia also recognizes the importance of establishing friendship for children with disabilities, who she says are:

'Not seriously [in school] for learning'. They have just come to school so that they enjoy their peers' company, and to develop the sense of love and selfidentity.

The importance Sophia puts on social inclusion has to be read in the context of the central importance of community in Tanzania (Kisanji, 1998). She also says, 'They can stay in one class for two years before they proceed to the next class', indicating that the school is flexible and allows some children to repeat grades in order to meet prescribed learning outcomes, rather than assuming that they would simply drop out. Similarly Rose and Justina reported that they had not learned sufficient sign language, and so had 'failed' those students with hearing impairments, despite having seated them at the front, ensured that their faces could be seen, and spoken 'loudly'. Being aware of what they do not know signals their desire to act on this (Kershner, 2014).

\section{Discussion}

Slee (2001, p. 172) has argued that inclusive education is an oxymoron since 'schools were never really meant for everyone. The more they have been called upon to include the masses, the more they have developed the technologies of exclusion and containment'. Indeed, there is plenty of evidence of such practices globally, including in materially rich environments (Alves, Andreasson, Karlsson, \& Miles, 2016). One of the reasons why we chose to focus on the Tanzanian teachers' 'knowledge and knowing' as a focus for this thematic issue, was pre- 
cisely because very few of the experienced teachers were practising 'exclusion and containment'. Instead they are responding to learners with disabilities as successfully as their training, the rigid curriculum and poor material conditions allow. They do not use the language of equality or inclusion, but are conscious that inclusion and exclusion co-exist in practice (Dyson, 1999). Furthermore, children with disabilities are not seen by most teachers as 'problems to be fixed'. They also show that disability can be seen within inclusive education as an opportunity for 'democratising and enriching learning' (UNESCO, 2017, p. 13).

The Tanzanian teachers adapt seating, their speech, posture and explanations, and create teaching and learning materials to enable greater participation and learning, including making use of assistive devices, as stipulated in the CRPD. In contrast to the NQTs, these experienced teachers go beyond generic strategies to adapt their pedagogy to specific individual impairments, are confident in using assistive devices, and strive to overcome material barriers of inadequate seating and large classes. Most importantly, they are aware that they 'do not know everything' and believe that change is possible (Kershner, 2014). They also demonstrate this by being willing to take risks and try things out in practice. We argue here that these teachers have developed some basic disability equality expertise as part of their everyday practice, without professing to be teaching inclusively, and without having had any specialist training. This sort of experiential learning is not unusual (see for example, Miles, 2009b), but tends to be unrecognised.

The General Comment has made some helpful recommendations about the possible focus of teacher training for inclusive education as a mainstream activity, which would require teacher educators to grapple with disability as a social construct. Despite the apparently strong inclusive policy focus in East and Southern Africa, there is no evidence of 'teacher training for inclusive education as a mainstream activity' (Riggall \& Croft, 2016, p. 12). Training courses are mainly offered to teachers of children with disabilities and emphasise special education approaches rather than disability equality. For some of the Tanzanian teachers, medical, socio-cultural and interactionist models of disability remain influential and are visible in their practice. Justina's account of her failure to create equal conditions, and her lack of sign language knowledge are representative of some of the other teachers' practice. This shows how disability inequality can be reproduced through a narrow conceptualisation of 'learning', for example, and through the use of punishment to control learners. By contrast, Rose's construction of disability is a transformative one, which sees her develop a more imaginative practice of ensuring that learners with disabilities grasp mathematical concepts and have direct sight of texts on an equal basis to their peers - a construction that benefits all learners, and provides a glimpse of the transformational education agenda envisaged by the SDGs.
Even so, it could be argued that the human rights debate, as enshrined in international policy, is out of step with the material inequalities of insufficient desks and books, and overcrowded curricula and classrooms in which many learners are routinely excluded, and in particular those with disabilities. An equal right to education is largely contingent on the material context (Vavrus \& Bartlett, 2012), and teachers' resistance to teaching equitably can undermine disability equality policies in any context. Exclusions here are structural, and rooted in material, physical, curricular and knowledge deficits.

\section{Conclusions}

We have argued that the experienced teachers' practices in Tanzania are moving unevenly, but discernibly towards disability equality. This is enabled by processes of inclusions in classrooms created by teacher autonomy, agency and reflective and imaginative practice, alongside material, attitudinal, structural, pedagogic and curricular barriers. This unevenness illustrates the limits of inclusive education as a construct and the considerable challenges that exist for full disability equality to take place. It also highlights the need for inclusive education to grapple with disability as a social construct. There is a need for academics and policy makers to consider the material as well as curricular and policy basis of inclusion. We suggest that a commitment to measuring the development of inclusive processes should be prioritized over narrow academic outcomes, and this would enable teachers to develop knowledge and expertise through collaborative learning.

Disability equality measures are more likely to develop in meaningful ways once inclusive classroom practices have become better established. Similarly, government commitment is needed to address the fragility, inconsistency and unaffordability of specialized knowledge and services. Children with disabilities will have a limited experience of inclusive education, if even the most basic assistive devices are not made available. Finally, it is important to emphasise that ongoing efforts to educate policy makers about the complexity of creating equitable education systems are just as vital to the meaningful achievement of the General Comment as preparing and supporting teachers to respond to diversity.

In summary, we have argued that the achievement of equality for learners with disabilities currently relies largely upon the ingenuity of ordinary classroom teachers. Disability equality should not, however, have to rely on this. Communication and dissemination of existing expertise developed within classroom and school contexts by experienced teachers (Kershner, 2104) would go a long way towards ensuring that adaptive pedagogy, clearly written texts, imaginative explanations, good use of assistive devices and classroom re-organization become commonplace in the physical 'place' of the classroom. In this sense, the teachers' inclusive practices can be seen as effective pedagogies which could inform 
teacher education colleges and policy makers. The reconstruction of disability in order to 'reimagine education' (Winzer \& Mazurek, 2017, p. 18) thus becomes probable, rather than locked into policy or theory, and merely aspirational.

\section{Acknowledgments}

We would like to express our deep appreciation to Professor Eustella Bhalalusesa from the University of Dar es Salaam, Tanzania, her research team, the many teachers who willingly gave up their time during the study, and $\mathrm{Dr}$ Cecilia Kimani for her professionalism in translating the data. We would also like to acknowledge the anonymous reviewers for their thorough engagement with this article and their many helpful suggestions.

\section{Conflict of Interests}

The authors declare no conflict of interests.

\section{References}

Akyeampong, K., Pryor, J., Lussier, K., \& Westbook, J. (2013). Improving teaching and learning of basic maths and reading in Africa: does teacher preparation count? International Journal of Educational Development, 33(3), 272-282.

Allan, J. (2010). The sociology of disability and the struggle for inclusive education. British Journal of Sociology in Education, 31(5), 603-619.

Alves, I., Andreasson, I., Karlsson, Y., \& Miles, S. (2016). Constructions of student identity in talk and text: A focus on special educational needs in Sweden and England. In D. Beach \& A. Dyson (Eds.), Equity in education in cold climates, in Sweden and England. London: The Tufnell Press.

Arbeiter, S., \& Hartley, S. (2002). Teachers' and pupils' experiences of integrated education in Uganda. International Journal of Disability, Development and Education, 49(1), 61-78.

Committee on the Rights of Persons with Disabilities. (2016). General comment No. 4 (2016) on the right to inclusive education. New York: United Nations.

Dyson, A. (1999). Inclusion and inclusions: Theories and discourses in inclusive education. In $\mathrm{H}$. Daniels \& P. Garner (Eds.), World yearbook of education 1999: Inclusive education (pp. 36-53). London: Kogan Page.

Glewwe, P., Park, A., \& Zhao, M. (2016). A better vision for development: Eyeglasses and academic performance in rural primary schools in China. Journal of Development Economics, 122, 170-182.

Grech, S. (2014). Disability, poverty and education: Perceived barriers and (dis)connections in rural Guatemala. Disability in the Global South, 1(1), 128-152.

Kershner, R. (2014). What do classroom teachers need to know about meeting special educational needs? In L.
Florian (Ed.), The Sage handbook of special education (2nd ed., Vol. 2, pp. 841-867). London: Sage.

Kisanji, J. (1998). The march towards inclusive education in non-Western countries: Retracing the steps. International Journal of Inclusive Education, 2(1), 55-72.

Malinga, J., \& Gumbo, T. (2016). Advocacy and lobbying: The road map from charity to human rights. In E. G. Iriate, R. McConkey, \& R. Gilligan (Eds.), Disability and human rights. Global perspectives. London: Palgrave Macmillan.

Miles, M., \& Hossain, F. (1999). Rights and disabilities in educational provision in Pakistan and Bangladesh Roots, rhetoric, reality. In L. Barton \& F. Armstrong (Eds.), Disability and human rights in education: Cross cultural perspectives. Buckingham, UK: Open University Press.

Miles, S. (2009a). Creating conversations: An inclusive approach to the networking of knowledge about education in southern contexts. PhD Thesis, Manchester: University of Manchester.

Miles, S. (2009b). Engaging with teachers' knowledge: Promoting inclusion in Zambia. Disability and Society, 24(5), 611-624.

Miles, S., \& Singal, N. (2010). The education for all and inclusive education debate: Conflict, contradiction or opportunity? International Journal of Inclusive Education, 14(1), 1-15.

Mmbaga, D. R. (2002). The inclusive classroom in Tanzania. Dream or reality? Stockholm: Institute of International Education, Stockholm University.

Pryor, J., Akyeampong, K., Westbrook, J., \& Lussier, K. (2012). Rethinking teacher preparation and professional development in Africa: An analysis of the curriculum of teacher education in the teaching of early reading and mathematics. Curriculum Journal, 23(4), 409-502.

Riggall, A., \& Croft, A. (2016). Eastern and Southern Africa regional study on the fulfilment of the right to education of children with disabilities. Reading, UK: Education Development Trust.

Singal, N., \& Muthukrishna, N. (2014). Education, childhood and disability in countries of the SouthRepositioning the debates. Childhood, 21(3), 293-307.

Slee, R. (2001). Social justice and the changing directions in educational research: The case of inclusive education. International Journal of Inclusive Education, 5(2/3), 167-177.

Terzi, L. (2008). Justice and equality in education. A capability perspective on disability and special educational needs. London: Continuum.

The United Republic of Tanzania. (2010). People with Disabilities Act, No 9. Dar-es-Salaam: The United Republic of Tanzania. Retrieved from http://www.usicd. org/doc/wcms_151288.pdf

United Nations. (1989). Convention on the rights of the child. New York: UN.

United Nations. (1993). The standard rules on the equal- 
ization of opportunities for persons with disabilities. New York: UN.

United Nations. (2006). Convention on the rights of persons with disabilities and optional protocol. New York: UN.

UNESCO. (1994). The Salamanca statement and framework for action on special needs education. Paris: UNESCO.

UNESCO. (2000). Education for all: Meeting our collective commitments. Notes on the Dakar framework for action. Paris: UNESCO.

UNESCO. (2012). Youth and skills: Putting education to work. Global monitoring report-Education for all. Paris: UNESCO.

UNESCO. (2017). A guide for ensuring inclusion and equity in education. Paris: UNESCO.

Vavrus, F., \& Bartlett, L. (2012). Comparative pedagogies and epistemological diversity: Social and material contexts of teaching in Tanzania. Comparative Education Review, 56(4), 634-658.

Wapling, L. (2016). Inclusive education and children with disabilities: Quality education for all in low and middle income countries. Bensheim: CBM. Retrieved from http://www.cbm.org/article/downloads/54741
/Quality_Education_for_All_LMIC_Evidence_Review _CBM_2016_Full_Report.pdf

Westbrook, J., Durrani, N., Brown, R., Orr, D., \& Pryor, J. (2014). Pedagogy, curriculum, teaching practice \& teacher education in developing countries. A rigorous literature review. London: Department for International Development.

Westbrook, J., \& Croft, A. (2015). Beginning to teach inclusively: An analysis of newly-qualified teacher pedagogy in lower primary classes in Tanzania. Teaching and Teacher Education, 51, 38-56.

Winzer, M., \& Mazurek, K. (2017). The Convention on the Rights of Persons with Disabilities. Reconstructing disability to reimagine education. In M. TejeroHughes \& E. Talbott (Eds.), The Wiley handbook of diversity in special education. Chichester: Wiley Blackwell.

World Health Organisation. (2011). World report on disability. Geneva, Switzerland: WHO.

World Health Organisation. (2014). Global cooperation on assistive technology. Geneva: WHO. Retrieved from http://www.who.int/phi/implementation/as sistive_technology/phi_gate/en

\section{About the Authors}
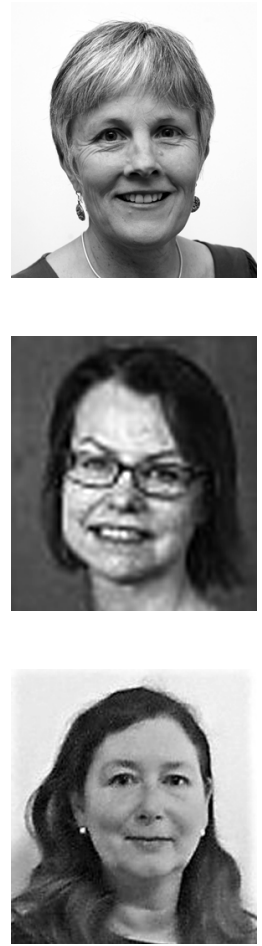

Susie Miles is a Senior Lecturer in Inclusive Education at the University of Manchester. Her research focuses on innovative ways of documenting and sharing practice in inclusive education, including the use of photography in educational research. She was the founding coordinator of the Enabling Education Network (EENET), a unique resource on the development of more inclusive educational approaches in low and middle-income countries, and was Save the Children UK's Disability Advisor for Southern and Eastern Africa.

Jo Westbrook is a Senior Lecturer in Education based in the Centre for International Education at the University of Sussex, UK and convenes the PhD in Education. Her research interests focus on teacher education, reading comprehension and equity in education through inclusive pedagogies in Sub-Saharan Africa. Currently Jo is working with Sightsavers and the University of Kyambogo in Uganda on an inclusive education project for all primary tutors and trainees.

Alison Croft is currently studying Audiological Science at University College London. She was formerly a lecturer in the Centre for International Education, University of Sussex. She has worked in research, policy and training for government and non-governmental organisations in many countries including as a regional special/inclusive education advisor in Namibia and as a support teacher for disabled children in mainstream classes in the UK. Her research interests focus on responses to student diversity at various levels of education systems. 